ISBN 978-81-936279-8-3

13th International Conference on Language, Literature, Social Sciences and Interdisciplinary Studies

(LLSSI-18)

London (UK) June 25-26, 2018

\title{
Adoption and use of Smartphones by the Elderly in Nigeria
}

\author{
Funmilola Olubunmi Omotayo \\ Africa Regional Centre for Information Science, University of Ibadan, Nigeria
}

\begin{abstract}
Smart phones are innovations that currently provide immense benefits and convenience to users in society. However, not all members of society are adopting and using the technology; more specifically the elderly (60+), who have less familiarity with ICTs as compared to the younger generation. Currently, there is minimal knowledge on the level of adoption and use of smartphones by the elderly in Nigeria. This study, therefore investigated adoption and use of smartphones by the elderly people in Nigeria. The study found that the use of smartphones by the elderly was low as majority of the elders had not adopted the use of the technology. Cost of smartphones, lack of knowledge of the benefit of smartphone use and perceived difficulty of use are some of the reasons for non-adoption. Those that have adopted complained about the interfaces on the phones, which are not suitable for use by them because of their poor eyesight, as well as problems experienced with the buttons on the phones which are too small for their feeble hands. The study recommends that smartphones suitable for the elderly should be made readily available and affordable to them because of their peculiarities.
\end{abstract}

Keywords: adoption and use, elderly people, ICT, Nigeria, smartphone

\section{Introduction}

Over the last decade, Information and Communication Technologies (ICTs) have significantly advanced. Admittedly, ICTs such as laptops, tablets and smartphones, have an important role in personal life (Anderson and Perrin, 2017). These technologies provide benefits for users as they access and manage information faster and easier. For almost three decades now, one of the fastest growing novel technologies in the ICT, and especially mobile phone market, is the smartphone. Smartphone is considered as one of the ubiquitous technologies in this present time as it allows users to connect to one another socially. Aside voice calls and text messaging; smartphones can be used for personal, educational, business, entertainment and a plethora of other purposes. One of the features that make smartphones very popular amongst youth is the ability to use them for social media such as Facebook, Instagram, You tube, Twitter, etc. Smartphone have many features and capabilities that enable users perform many functions such as e-mailing, chatting, internet banking, photograph taking, audio and video recording, among other uses. This makes the uses of smartphones prevalent among the youths. Since its introduction early 1990s, smartphones have brought about significant and unprecedented changes in the way humans interact and share information and the number of users worldwide has grown geometrically. Newzoo's April 2017 Global Mobile Market Report shows the percentage of the population owning a smartphone in Nigeria as $14.8 \%$, translating to 28.4 million users out of a population of 191.8 million.

The introduction of smartphones has impacted every sphere of human life: communication, entertainment, business, health, journalism, education, among others. In terms of usage, smartphones can benefit various users, be it children, young adults and older adults. It can arguably be described as the converged ultimate in mobile consumer products. Smartphones allow users to connect to the internet and run many applications (apps) as well as sending text messages and making phone calls. For the elderly whose children and loved ones don't live with, smartphones can help them to be constantly in touch. Smartphones can also serve as a calendar, alarm, GPS tracker, and an entertainer. In case of an emergency, smartphone can be of great benefit to the elderly. 
In 2002, the World Health Organisation described population ageing as one of humanity's greatest triumphs as well as one of the world's greatest challenges and that global ageing is putting increased economic and social demands on all countries. In addition, United Nations, 2010) stated that due to advances in medicine and improvements in the quality of life, countries around the globe are facing the prospect of an ageing population. Thus the proportion of older adults in the population all over the world is increasing. With population projections estimating a rise in the old dependency ratio and increasing technological developments all over the world, it is no surprise that researchers are looking at how technologies can be used to support older adults. ICTs offer opportunities in providing support and enhancing the daily lives of elderly people. Some of the technologies that have been designed for the elderly include ambient assisted living technologies (Sainz-Salces et al. 2006), technologies to monitor activities of daily living (Bieber et al, 2010), health management systems (Coughlin, Pope \& Leedle, 2006), and interactive 'wellness' technologies. However, the vast majority of this aged population did not have the opportunity to learn and use technology during their younger years. Thus, because of a growing ageing population and an increasing reliance on technology to conduct activities associated with daily living, research into technology usage by the elderly is seen as crucial in enabling them to remain relevant, active, independent and vitally engaged in the society (Goyal \& Dixit, 2008).

A vast amount of research has demonstrated that the use of smartphones has the potential to enable older adults to improve their quality of life and reduce healthcare costs (Anderson and Perrin, 2017; Caprani et al., 2012; Pheeraphuttharangkoon, 2015). Researchers also regard these applications as a great tool to support autonomous living while maintaining quality of life among the elderly as they experience declines in perceptual, motor, and cognitive abilities due to natural aging (Poushter, 2016). However, not all members of society are adopting and using smartphones; more specifically, the elderly (60+), who have less familiarity with ICTs, compared to the younger generation, having being born at least 55-60 years ago when personal computers were not yet commonplace. Moreover, many smartphones are not designed to take care of the peculiarities associated with this age group as the phones often have complicated navigation steps and the interface is not suitable for use by the elderly.

It has been found that within the older population in Nigeria, the rate of adoption of this novel technology is still low and currently, there is minimal knowledge of the reasons for older adults in Nigeria adopting and using smartphones. Therefore, understanding and examining the usage level and factors that influence use of smartphones among the elderly in Nigeria is important and timely. This study, thus, investigated the level of adoption and use of smartphones among the elderly people in Nigeria, the activities the phones are used for, factors influencing use, benefits derive from use, and challenges encounter while using the phones. In this paper, "the elderly" are defined as people over the age of 60 in accordance with United Nations standard (United Nations, 2008; WHO, 2002). The terms "seniors", "elders" and "older adults" are used interchangeably in this paper to denote adults who are ages 60 and older.

\section{Research Design, Location and Population of the Study}

The study adopted the descriptive survey research design. The location of the study is Saki, Oyo State, Nigeria. Saki is a semi-urban town, situated in the northern part of Oyo State in Southwestern Nigeria, with a population of about 700,000 (the population was 388,255 as at 2006 population census). The population of the study comprised of all elderly people in the town. However, owing to the difficulty in obtaining a comprehensive and up-to-date population of elderly people in the town, convenience and snowball sampling technique was used to select 383 elderly people who were willing to participate in the study. Questionnaire, complemented with interview were used to elicit data from the elders because it was envisaged that interview would provide an additional opportunity to allow the elders share their experiences with regards to adoption and use of smartphones. The respondents were therefore asked to fill a questionnaire and were also 
engaged in discussions to bring out salient and peculiar experiences they might have had with regards to use of smartphones.

\section{Results and Discussion}

The findings of the study are discussed under the following headings: demographic information of the respondents, period of adoption of smartphone, frequency of use, features used on the phones, factors influencing use, benefits derived from using the phones, challenges experience while using the phone. Table I presents the demographic characteristics of the elderly.

TABLE I: Socio-Demographic Characteristics of Respondents

\begin{tabular}{|c|c|c|c|}
\hline Characteristic & Category & Frequency & Percent (\%) \\
\hline \multirow[t]{2}{*}{ Sex } & Male & 220 & 57.4 \\
\hline & Female & 163 & 42.6 \\
\hline \multirow[t]{4}{*}{ Age } & $60-65$ years & 180 & 47.0 \\
\hline & $66-70$ years & 93 & 24.3 \\
\hline & $71-75$ years & 72 & 18.8 \\
\hline & Above 75 years & 38 & 9.9 \\
\hline \multirow{9}{*}{$\begin{array}{l}\text { Highest Educational } \\
\text { qualification }\end{array}$} & No education & 14 & 3.7 \\
\hline & Primary education or equivalent & 31 & 8.1 \\
\hline & Standard six, Modern School/Secondary & 104 & 27.2 \\
\hline & Grade II, Ordinary National & & \\
\hline & $\begin{array}{l}\text { Diploma/National Certificate of } \\
\text { Education/equivalents }\end{array}$ & 182 & 47.5 \\
\hline & HND or First degree & 28 & 9.1 \\
\hline & Masters & 15 & 3.9 \\
\hline & Doctoral & 0 & 0 \\
\hline & Others (Professionals, etc.) & 2 & 0.5 \\
\hline \multirow[t]{5}{*}{ Marital status } & Single & 0 & 0 \\
\hline & Married & 248 & 64.8 \\
\hline & Separated & 34 & 8.9 \\
\hline & Divorced & 9 & 2.3 \\
\hline & Widow/Widower & 92 & 24.0 \\
\hline \multirow[t]{3}{*}{ Religion } & Christianity & 201 & 52.5 \\
\hline & Islam & 175 & 45.7 \\
\hline & Traditional & 7 & 1.8 \\
\hline \multirow{3}{*}{$\begin{array}{l}\text { Occupation (presently or } \\
\text { before retirement) }\end{array}$} & Public servant & 129 & 33.7 \\
\hline & Self-Employed & 110 & 28.7 \\
\hline & Retired/Unemployed & 144 & 37.6 \\
\hline Present monthly income & Less than $\$ 50,000$ (about $\$ 138.88$ )* & 44 & 11.5 \\
\hline \multirow[t]{2}{*}{ (Pension plus other sources) } & $\$ 50,000-\$ 100,000(\$ 138.88-\$ 277.78)$ & 255 & 66.6 \\
\hline & Above $\$ 100,000(-\$ 277.78)$ & 84 & 21.9 \\
\hline How would you describe & Poor & 52 & 13.6 \\
\hline \multirow[t]{2}{*}{ your health status } & Good & 158 & 41.2 \\
\hline & Very good & 173 & 45.2 \\
\hline
\end{tabular}

* Calculated at $\$ 360$ to $\$ 1$

About $57.0 \%$ of the elderly were males while $43.0 \%$ were females. Most of the elders (45.2\%) described their health status as very good. Table II presents the results of the types of phones used by the elderly. 
TABLE II: Types of mobile phones used by the Elderly and frequency of use

\begin{tabular}{llll}
\hline \hline Characteristic & Category & Frequency & Percent $\mathbf{( \% )}$ \\
\hline Type of phone used & Basic (Regular) Phone & 223 & 58.2 \\
How long the elderly have & Smartphone & 160 & 41.8 \\
been using phones (years) & & & \\
& & 48 & 12.5 \\
Basic Phone & 1-5 years & 106 & 27.7 \\
& 6-10 years & 69 & 18.0 \\
& More than 10 years & 122 & 31.9 \\
Smartphone & 1-5 years & 38 & 9.9 \\
& 6-10 years & 0 & 0 \\
& More than 10 years & 223 & 58.2 \\
Basic Phone & Daily & 0 & 0.0 \\
& Weekly & 0 & 0.0 \\
& Fortnightly & 0 & 0.0 \\
& Monthly & 145 & 37.9 \\
Smartphone & Daily & 15 & 3.9 \\
& Weekly & 0 & 0.0 \\
\hline \hline
\end{tabular}

The results show that less than half of the elders (41.8\%) had smartphones. Table III presents the findings on the features of smartphone used by the elders.

Table III: Features of Smartphone used

\begin{tabular}{lll}
\hline \hline Features of smartphones used & Frequency & Percent $\mathbf{( \% )}$ \\
\hline Voice call & 160 & 100.0 \\
Messaging & 160 & 100.0 \\
Browser & 65 & 40.6 \\
Camera & 149 & 93.1 \\
Clock & 123 & 76.9 \\
Radio & 151 & 94.4 \\
Calculator & 72 & 45.0 \\
Flash light & 110 & 68.8 \\
Voice Recorder & 70 & 43.8 \\
Search tool & 12 & 7.5 \\
Calendar & 92 & 57.5 \\
Alarm & 140 & 87.5 \\
Reminder & 68 & 42.5 \\
Music recorder and player & 139 & 86.9 \\
Video recorder and player & 139 & 86.9 \\
Call logs & 160 & 100.0 \\
\hline \hline
\end{tabular}

Within the older adults, $41.8 \%$ who had smartphones, voice call, messaging, camera, radio, and call logs are the features of smartphone used by all of them. Some other features used by them are: alarm (87.5\%), browser (75\%), flash light $(68.8 \%)$, music recorder and player $(68.8 \%)$, video recorder and player $(68.8 \%)$, calendar $(56.3 \%)$, clock $(43.8 \%)$, voice recorder/notes $(43.8 \%)$, calculator $(37.5 \%)$, reminder $(37.5 \%)$, and search tool $(12.5 \%)$ in descending order. This finding is corroborated with findings from the interview sessions in which all the elders said that they used the voice and text messaging features of the phone regularly. Majority of the elders also mentioned that there is no day they didn't use their phones to listen to radio. Some responses:

There is no day I don't use my phone to call or send text messages to people. As a matter of fact, I call my children every day because they don't live in this town. (Elder 5, female, 72 years)

I use my smartphone to make voice calls every day because there is always the need to find out information from people or simply greet my children, relatives and friends, and know how they are faring. (Elder 8, male, 68 years)

Table IV shows the activities the elders who had smartphones used their smartphones to perform. 
TABLE IV: Smartphone usage

\begin{tabular}{lll}
\hline \hline Smartphone usage & Frequency & Percent (\%) \\
\hline Making phone call & 160 & 100.0 \\
Making a video call such as Skype, Viber, etc. & 39 & 24.4 \\
Messaging (SMS/text messaging) & 160 & 100.0 \\
Browsing or surfing website(s) & 65 & 40.6 \\
Electronic mail (E-mail) & 42 & 26.3 \\
Downloading applications (apps) & 110 & 68.8 \\
Using social networks (e.g. Facebook, Twitter, Instagram, LinkedIn, Google+) & 150 & 93.8 \\
Taking a pictures & 149 & 93.1 \\
Music recording and playing & 139 & 86.9 \\
Video recording and playing & 139 & 86.9 \\
Voice Recording & 70 & 43.8 \\
Using the flash light & 110 & 68.8 \\
To check for dates (Calendar) & 92 & 57.5 \\
For reminders or waking up & 123 & 76.9 \\
To search for words in the dictionary & 12 & 7.5 \\
To check weather forecast & 0 & 0.0 \\
To calculate figures & 72 & 45.0 \\
To check for time & 123 & 76.9 \\
Reading of online newspapers & 32 & 20.0 \\
Listening to radio & 151 & 94.4 \\
Internet banking & 29 & 18.1 \\
\hline \hline
\end{tabular}

* Respondents were asked to tick as many option as applicable

As also revealed in Table IV, voice calling, text messaging, taking of photographs and listening to radio are the major activities the elders used their smartphones to perform. Majority of the elders also used their smartphones for social networking such as Facebook, Instagram and YouTube so they became more informed about their friends' activities, news, and status. Also, they could make sure their friends were informed about themselves. Some of the elders described that the use of Facebook had become part of his life and their smartphones provided the opportunity to "stay connected". However, the interview sessions revealed that none of the elders used the LinkedIn and Twitter apps. Some of the responses from the interview session also corroborated this:

I use my phone to take my pictures and send to my children who are living abroud. I also use the facebok to check the pictures of my children and friends (Elder 2, female, 66 years)

My smartphone is my companion. Apart from using it to call my children, I use it to listen to radio, as alarm, to check time, to play christian music. I also use it as my torch light when i wake up in the night to urinate (Elder 15, female, 71 years)

It's a common thing now seeing people use their phones to take pictures, especially at parties or churches. People are always sharing their pictures for their friends' comments. I always find this amusing and I keep myself entertained by checking these pictures on Facebook and Instagram. (Elder 10, female, 67 years)

Majority of the elders also used the phones to remind them of events or wake up, record and play music or videos, and download applications, browse the internet and check dates. The findings reveal that none of the elders used smartphone to check weather forecast, while very few of them also used the phones to read online newspapers and carry out internet banking services. This shows that the elders preferred listening to radio for news rather than reading it on their phones. These results are in tandem with the findings of Nwachukwu \& Onyenankeya (2018), Wang, Xiang \& Fesenmaier (2016). Table V present the results of factors that influenced adoption and use of smartphone by the elders. 
TABLE V: Factors influencing adoption and use of smartphone by the elders

\begin{tabular}{|c|c|c|c|c|c|c|}
\hline \multirow[b]{2}{*}{ Factors influencing adoption and use of smartphone } & \multicolumn{2}{|c|}{ Agreed } & \multicolumn{2}{|c|}{ Disagreed } & \multicolumn{2}{|c|}{ Don't Know } \\
\hline & Freq & $(\%)$ & Freq & $(\%)$ & Freq & $(\%)$ \\
\hline Benefits I envisaged to derive from smartphones influenced me & 149 & 93.1 & 10 & 6.3 & 1 & 0.6 \\
\hline I feel smartphone is more useful than the basic phone & 153 & 95.6 & 7 & 4.4 & 0 & 0.0 \\
\hline I believe using smartphone fits well with my life style & 119 & 74.4 & 41 & 25.6 & 0 & 0.0 \\
\hline I think using smartphone would be easy for me & 101 & 63.1 & 59 & 36.9 & 0 & 0.0 \\
\hline $\begin{array}{l}\text { I think learning how to use smartphone would not be difficult for } \\
\text { me }\end{array}$ & 131 & 81.9 & 29 & 18.1 & 0 & 0.0 \\
\hline I have the knowledge required to use smartphone & 127 & 79.4 & 27 & 16.9 & 6 & 3.7 \\
\hline I have the resources necessary to use smartphone (time, money) & 152 & 95.0 & 6 & 3.8 & 2 & 1.2 \\
\hline $\begin{array}{l}\text { I think I would always find someone to assist me with using } \\
\text { smartphone when I need help }\end{array}$ & 111 & 69.4 & 49 & 30.6 & 0 & 0.0 \\
\hline I think it would be fun to use a smartphone & 152 & 95.0 & 8 & 5.0 & 0 & 0.0 \\
\hline $\begin{array}{l}\text { I think using smartphone would make me feel that I still belong to } \\
\text { the society }\end{array}$ & 159 & 99.4 & 1 & 0.6 & 0 & 0.0 \\
\hline I believe I would derive fun using my smartphone & 152 & 95.0 & 4 & 2.5 & 4 & 2.5 \\
\hline $\begin{array}{l}\text { I have had opportunity to see people using smartphones before } \\
\text { using it }\end{array}$ & 78 & 48.7 & 82 & 51.3 & 0 & 0.0 \\
\hline $\begin{array}{l}\text { My children/spouse/relatives influenced my adoption and use of } \\
\text { smartphone }\end{array}$ & 152 & 95.0 & 8 & 5.0 & 0 & 0.0 \\
\hline My friends use smartphones and encouraged me to also adopt it & 81 & 50.6 & 79 & 49.4 & 0 & 0.0 \\
\hline $\begin{array}{l}\text { I saw the advertisement of smartphone and that influenced my } \\
\text { adoption and use }\end{array}$ & 17 & 10.6 & 143 & 89.4 & 0 & 0.0 \\
\hline I intend to use smartphone as much as possible & 156 & 97.5 & 4 & 2.5 & 0 & 0.0 \\
\hline I intend to continue using smartphone & 156 & 97.5 & 4 & 2.5 & 0 & 0.0 \\
\hline
\end{tabular}

As shown in Table $\mathrm{V}$, the factors that influenced the elders' use of smartphones could be summarised as perceived usefulness/perceived value of smartphones, ease of use, perceived enjoyment or fun derive from use, facilitating conditions, and social influence/subjective norms. The results also show that the elders had continuance intention of using smartphones. Table VI presents the results of factors influencing non-adoption of smartphone by the non-adopters.

TABLE VI: Factors influencing non-adoption and use of smartphone by the elders

\begin{tabular}{|c|c|c|c|c|c|c|}
\hline \multirow[b]{2}{*}{ Factors influencing non adoption and use of smartphone } & \multicolumn{2}{|c|}{ Agreed } & \multicolumn{2}{|c|}{ Disagreed } & \multicolumn{2}{|c|}{ Don't Know } \\
\hline & Freq & $(\%)$ & Freq & $(\%)$ & Freq & $(\%)$ \\
\hline I do not perceive any benefit from the use of smartphone & 164 & 73.5 & 56 & 25.1 & 3 & 1.4 \\
\hline I feel the basic phone is more useful than smartphone & 201 & 90.1 & 22 & 9.9 & 0 & 0.0 \\
\hline I believe using smartphone is not useful and suitable for me & 141 & 63.2 & 82 & 36.8 & 0 & 0.0 \\
\hline I don't think using smartphone fits well with my life style & 118 & 53.0 & 96 & 43.0 & 9 & 4.0 \\
\hline I find that using the basic phone is easy for me & 199 & 89.2 & 24 & 10.8 & 0 & 0.0 \\
\hline I think smartphone is difficult to use & 192 & 41.3 & 31 & 13.9 & 0 & 0.0 \\
\hline Learning how to use smartphone could be difficult for me & 170 & 76.2 & 45 & 20.2 & 8 & 3.6 \\
\hline I do not have the knowledge required to use smartphone & 174 & 78.0 & 38 & 17.0 & 11 & 5.0 \\
\hline $\begin{array}{l}\text { I do not have the resources necessary to use smartphone (time, } \\
\text { money) }\end{array}$ & 69 & 31.0 & 139 & 62.3 & 15 & 6.7 \\
\hline I may consider using smartphone in the future & 159 & 71.3 & 58 & 26.0 & 6 & 2.7 \\
\hline I may use smartphone if I could get help to put me through & 120 & 53.8 & 97 & 43.5 & 6 & 2.7 \\
\hline I don't think I would use smartphone in the future & 84 & 37.7 & 129 & 57.8 & 10 & 4.5 \\
\hline
\end{tabular}

Some of the factors that have prevented some of the elderly from using smartphones could be summarised into lack of skill, lack of knowledge of the benefit of smartphone use, perceived difficulty of use, and fear of difficulty that could be experienced while learning to use. Majority (62.3\%) of the non-adopters however did not agree that they do not have the resources necessary to use smartphone. These findings are in tandem with some previous studies. Some of these barriers have also been identified by past studies such as Caprani et al., 2012; Chen, Chan, \& Chan, (2012), McGaughey, Zeltmann \& McMurtrey (2013) and Mohadisdudis \& Ali (2014). Table VII presents the results of the factors influencing adoption and use of smartphone by the elders. The findings, however, reveal that majority of the non-adopters $(71.3 \%)$ had the intention to adopt and use smartphones in the future. This call for smartphone designers, manufacturers and marketers to intensify efforts 
into making this group of non-adopters adopts the use of smartphones. The benefits of smartphone use could be highlighted in advertisement and other promotional activities to sensitise them.

\section{Conclusion}

The study concludes that the adoption and use of smartphone by elderly people in Saki, Nigeria is low as many of them remain largely disconnected from the digital revolution. The study found that the elders had continuance intention of using smartphones, and majority of the non-adopters had the intention to adopt and use smartphones in the future. The study recommends that smartphones suitable for the elderly should be designed, made readily available and affordable to them because of their peculiarities. In addition, stakeholders can help provide the learning resources on smartphones use and interesting applications, compatible with this age group so as to ensure adoption and continued use.

\section{References}

[1] M. Anderson and A. Perrin, "Tech adoption climbs among older adults," Pew Research Center: Internet and Technology, May 17, 2017. http://www.pewinternet.org/2017/05/17/tech-adoption-climbs-among-older-adults/

[2] G. Bieber, P. Koldrack, C. Sablowski, C. Peter, and B. Urban, "Mobile physical activity recognition of standup and sit-down transitions for user behaviour analysis," presented at the PETRA'10 Proceedings of the 3rd International Conference on PErvasive Technologies Related to Assistive Environments, no. 50, June 23 - 25 , 2010, Samos, Greece: ACM, pp. 1-5. https://doi.org/10.1145/1839294.1839354

[3] N. Caprani, J. Doyle, M. J. O’Grady, C. Gurrin, N. E. O’Connor, B. Caufield, G. M. P. O’Hare, “Technology use in everyday life: Implications for designing for older users," In: iHCI 2012: 6th Annual Irish Human Computer Interaction (HCI) Conference, 20-21 June 2012, Galway, Ireland. http://doras.dcu.ie/17097/1/iHCI_paper.pdf

[4] K. Chen, A. H. S. Chan, and S. C. Chan, "Gerontechnology acceptance by older Hong Kong people," Gerontechnology, vol. 11 no. 2, pp. 102-111, 2012. http://dx.doi.org/10.4017/gt.2012.11.02.524.00

[5] J. F. Coughlin, , J. E., Pope and B. R. Leedle, Jr., "Old age, new technology, and future innovations in disease management and home health care," Home Health Care Management and Practice, vol. 18, no. 3, pp. 196-207, 2006. https://doi.org/10.1177/1084822305281955

[6] V. C. Goyal and U. Dixit, "Technology for safety and protection of elderly," In S. Bhatia, M.Cherian and J. R. Gupta (Eds.), Protection of life and property of senior citizens in India, All India Senior Citizens' Confederation (AISCCON), Navi Mumbai, 2008.

[7] R. E., McGaughey, S. M. Zeltmann, and M. E. McMurtrey, "Motivations and obstacles to smartphone use by the elderly: developing a research framework," International Journal of Electronic Finance, vol. 7, no. 3/4, pp. 177-195, 2013. https://doi.org/10.1504/IJEF.2013.058601

[8] H. M. Mohadisdudis and N. M. Ali, "A study of smartphone usage and barriers among the elderly," User Science and Engineering (i-USEr), 2014 3rd International Conference on User Science and Engineering (i- USEr), Shah Alam, Malaysia. 2-5 Sept. 2014, 109-114, 2014, https://doi.org/10.1109/IUSER.2014.7002686

[9] Newzoo. Top 50 Countries by Smartphone Users and Penetration. Available at: https://newzoo.com/insights/rankings/top-50-countries-by-smartphone-penetration-and-users/

[10] C. Nwachukwu and K. Onyenankeya, "Use of smartphones among college students in Nigeria: revelations and reflections”, Journal of Communication, vol. $8 \quad$ no. $\quad 2$, pp. $171-182, \quad 2018$. https://doi.org/10.1080/0976691X.2017.1396007 
[11] S. Pheeraphuttharangkoon, "The adoption, use and diffusion of smartphones among adults over fifty in the UK," A Thesis submitted to the University of Hertfordshire in partial fulfilment of the requirements for the degree of doctor of philosophy, Management, Leadership and Organisation Business School, University of Hertfordshire, pp. 1-489, 2015.

[12] J. Poushter, Smartphone ownership and internet usage continues to climb in emerging economies. Pew Research Center: Global Attitudes and Trends, February 22, 2016.

http://www.pewglobal.org/2016/02/22/smartphone-ownership-and-internet-usage-continues-to-climb-inemerging-economies/

[13] F. J. Sainz-Salces, M. Baskett, D. Llewelyn-Jones, and D. England, “Ambient interfaces for elderly population at home,” In: Cai Y., Abascal J. (eds.) Ambient Intelligence in Everyday Life, Lecture Notes in Computer Science, vol. 3864. Berlin, Heidelberg: Springer, 2006, pp. 256-284. https://doi.org/10.1007/11825890_13

[14] United Nations, World Population Prospects: The 2008 Revision - Population Database, 2008. http://www.un.org/esa/population/publications/wpp2008/wpp2008_highlights.pdf

[15] D. Wang, Z. Xiang, and D. R. Fesenmaier, "Smartphone use in everyday life and travel," Journal of Travel Research, vol. 55 no. 1, pp. 52-63, 2016. https://doi.org/10.1177/0047287514535847

[16] World Health Organisation, Active ageing: A policy framework. A contribution of the World Health Organization to the Second United Nations World Assembly on Ageing, Madrid, Spain, April 2002.

[17] United Nations, "World Population Policies 2009," Department of Economic and Social Affairs, Population Division, New York, 2010.

http://www.un.org/esa/population/publications/wpp2009/Publication_complete.pdf 